American J. of Engineering and Applied Sciences 1 (1): 76-81, 2008

ISSN 1941-7020

(C) 2008 Science Publications

\title{
Investigation of Pile- Soil Interaction Subjected to Lateral Loads in Layered Soils
}

\author{
A. Avaei, Abdoul R. Ghotbi and M. Aryafar \\ Shahid Bahonar University, Department of Civil Engineering, Kerman, Iran
}

\begin{abstract}
To stabilize infrastructures such as tall buildings, bridges, etc., piles are used to resist lateral loads created from earth pressure, wind, waves and earthquake extensively. Pile design requires understanding of how the load is transferred from a pile to surrounding soil and vice versa. Pile properties, soil stress-strain behavior and pile-soil interaction play important roles in pile-response subjected to lateral loads. A study was carried out to investigate the effects of above-mentioned parameters on pile-soil behavior subjected to lateral forces. A comparison was made between the results derived from finite difference and equivalent spring methods by writing a computer program and using a civil engineering package, respectively.
\end{abstract}

Key words: Pile-soil interaction, lateral loads, finite difference method, equivalent spring method

\section{INTROUDUCTION}

The proper assessment of lateral displacement and internal forces of piles under lateral loads in order to design them in the projects such as bridges, marine structures, platforms and huge industrial buildings is of paramount importance. Since the considerable part of stability and resistance of a structure as well as its safety factor depend on its foundation and considering that, deep foundations are so expensive, therefore optimum design and determination of the thorough behaviour of piles are of main importance. Generally speaking, 3 main factors are very important to be considered in most of the projects including soil stress, bearing capacity of pile and lateral displacement of pile, respectively. It is noteworthy to be implied that, in most of the practical projects, the displacement factor is the controlling one. Despite the recent progress in all sciences including soil mechanics, determination of piles behaviour especially under lateral loads and in the layered soils is so difficult. Physical and mechanical properties of soil, variety of piles in terms of the implied materials, the length of the piles, the diameter, the section shape and the employed empirical method are led to complexity of the interaction between pile and the surrounding soil, therefore many researchers like REESE, MATLOCK etc., have been pursuing the methods for pile design using combination of the theoretical and the experimental methods. Other researchers like BOWELS used also the mathematical methods for this propose. Since behaviour of piles as well as soils is completely various and it is naturally too hard to define a homogenous soil, therefore in the present research, we shall investigate the different methods and parameters in determining the different behaviour of soil ${ }^{[1-5]}$.

In this research, two methods are investigated in the layered soils. These methods include the Finite Difference Method (FDM) which in order to use it, a computer program has been written in Turbo Pascal environment and the equivalent spring method which it has been applied using SAP2000 package.

\section{METHODS OF ANALYSIS}

In this research, considering the variously presented methods, the two of them which are very useful and applicable are employed in order to analyze the vertical piles under the lateral loads. These methods are the FDM and the equivalent spring method, respectively. In the first method by writing a computer program, the amount of displacement and bending moment as a function of $\mathrm{z}$ from the top of the pile are calculated. In the second method, the equivalent spring method, pile is modeled in SAP2000 package. In this method using WINKLER theory of equivalent spring, the surrounding soil is modeled by the springs with the stiffness K. All piles are analyzed as the free head piles and in all analysis, the number of layers around the piles is 2 and the number of those under the piles is 1 .

Corresponding Author: Abdoul R .Ghotbi, Department of Civil Engineering, Shahid Bahonar University, Kerman, Iran Tel: +98 1913182347 Fax: +98 2133939450 
Finite Difference Method (FDM): A beam with constant section is considered. This beam is continued along $\mathrm{X}$ direction and burdens a lateral load $\mathrm{F}$ above itself. Also the displacement along $\mathrm{Z}$ is $\mathrm{W}$ and the bending moment is $\mathrm{M}$. from material strength:

$$
\begin{gathered}
\frac{d^{2} M}{d x^{2}}=-f \\
\text { EI } \frac{d^{2} w}{d x^{2}}=-M
\end{gathered}
$$

If the soil reaction is also added in addition to the external load $\mathrm{F}$, assuming that the soil reaction corresponds to the lateral displacement of beam, therefore the above equations can be written as follows:

$$
\frac{d^{2} M}{d x^{2}}=-f+k w
$$

where, $\mathrm{k}$ is the sub grade modulus.

The algorithm of the numerical solution: The mentioned beam is divided into the $\mathrm{n}$ equal parts and the equilibrium equations are written for each part (Fig. 1):

$$
\begin{aligned}
\mathrm{Q}_{\mathrm{i}+1}-\mathrm{Q}_{\mathrm{i}}= & -\mathrm{p}_{\mathrm{i}}-\mathrm{f}_{\mathrm{i}+1} \mathrm{~d}_{\mathrm{i}+1}+ \\
& \frac{1}{2} \mathrm{R}_{\mathrm{i}+1}\left(\mathrm{w}_{\mathrm{i}}+\mathrm{w}_{\mathrm{i}+1}\right)
\end{aligned}
$$

where, $d_{i+1}$ is the length of the element $i+1, R_{i+1}=$ $K_{i+1} d_{i+1}$ and the subgrade modulus is supposed to be constant along the element. Writing the equilibrium equations for the element $\mathrm{i}$ and adding it to Eq. 4, one can determine:

$$
\begin{aligned}
& Q_{i+1}-Q_{i-1}= \\
& -p_{i}-p_{i-1}-f_{i+1} d_{i+1}-f_{i} d_{i}+ \\
& \frac{1}{2} R_{i} w_{i-1}+\frac{1}{2}\left(R_{i}+R_{i+1}\right) w_{i}+\frac{1}{2} R_{i+1} w_{i+1}
\end{aligned}
$$

Now, the moment equilibrium is written for the element $i+1$ around the element center:

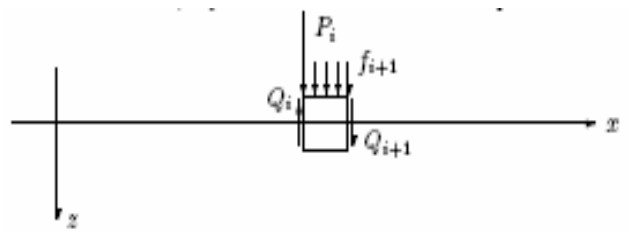

Fig. 1: Assumed element along with the implemented load

$$
\begin{aligned}
& \mathrm{M}_{\mathrm{i}+1}-\mathrm{M}_{\mathrm{i}}= \\
& \frac{1}{2}\left(\mathrm{Q}_{\mathrm{i}+1}+Q j\right) \mathrm{d}_{\mathrm{i}+1}- \\
& \frac{1}{2} \mathrm{p}_{\mathrm{i}} \mathrm{d}_{\mathrm{i}+1}
\end{aligned}
$$

Substituting $i$ for $i+1$ in Eq. 6, we have the moment balance in the element $\mathrm{i}$ and by adding these two relations and then combining them with Eq. 5 one leads to:

$$
\begin{aligned}
& \frac{1}{\mathrm{~d}_{\mathrm{i}+1}} \mathrm{M}_{\mathrm{i}+1}-\left(\frac{1}{\mathrm{~d}_{\mathrm{i}+1}}+\frac{1}{\mathrm{~d}_{\mathrm{i}}}\right) \mathrm{M}_{\mathrm{i}}+ \\
& \frac{1}{\mathrm{~d}_{\mathrm{i}}} \mathrm{M}_{\mathrm{i}-1}-\frac{1}{4}\left(\mathrm{R}_{\mathrm{i}+1} \mathrm{~W}_{\mathrm{i}-1}=\right. \\
& \frac{1}{2}\left(\mathrm{~d}_{\mathrm{i}} \mathrm{f}_{\mathrm{i}}+\mathrm{d}_{\mathrm{i}+1} \mathrm{f}_{\mathrm{i}+1}\right)-\mathrm{p}_{\mathrm{i}}
\end{aligned}
$$

This is the first fundamental equation for solving the problem and is the numerical equivalent of Eq. 3. The second fundamental equation is Eq. 2 which is written according to the similar analyses as fallows:

$$
\begin{aligned}
& \frac{E I}{d_{i+1}} w_{i+1}-\left(\frac{E I}{d_{i+1}}+\frac{E I}{d_{i}}\right) w_{i}+ \\
& \frac{E I}{d_{i}} w_{i-1}+\frac{1}{4} d_{i+1} M_{i+1}+ \\
& \frac{1}{4}\left(d_{i+1}+d_{i}\right) M_{i}+\frac{1}{4} d_{i} M_{i+1}=0
\end{aligned}
$$

Equation 7 and 8 are the exact estimation of Eq. 2 and 3 by using the central FDM.

Explanation of the av-pile computer program: This program has been written by TURBO PASCAL which is one of the most powerful languages of programming. This program is a FDM program in which by introducing the different properties of pile material, loading and soil around and under the pile and dividing the pile into the $\mathrm{n}$ equal parts and then calculating the equilibrium equations for each independent part, one leads to the general balance of the system. This program can show the output results such as displacement, bending moment and shear strength along the pile. Avpile is a complete program for analyzing a pile under lateral loads. This program is run rapidly. Since the input values are only limited to the properties of the investigating problem, it can be modeled very fast and also it can be used in the practical projects. The program in a graphics 
environment, at first receives the properties of the pile including, the length, the diameter, the stiffness (EI) and the number of soil layers around the pile (Maximum 10 layers can be introduced) and the number of those under the pile (Maximum 10 layers can be introduced). In the second part, the loading properties are asked which they could be implemented as the shear force and the bending moment at the head of the pile. The amount of the convergent tolerance and the number of the iteration in a common FDM project is 0.001 and 100 , respectively which it could be varied depending on the investigating project. Finally, the properties of the soil around and under the pile are asked which they mainly include the modulus of elasticity and the poisson ratio. By clarifying these data, the program is automatically run. The output results of the program including displacement, bending moment and shear force in the discrete points of the pile element are saved in a text file. These results can be exported to Excel (A statistical soft ware) and finally the comparative figures can be plotted. It should be implied that all input and output units of the program are in SI $(\mathrm{KN}-\mathrm{m})$ system and changing of them is not allowed. Avpile can analyze short and long piles. Also, it is capable to create the different types of loading such as bending moment along with lateral loads. The soil layers around and under the pile can be increased to 10 layers and there is a possibility inside the program to increase the layers, However increasing the layers would decrease the accuracy of the problem solving as well as the speed of the program. In the commonly practical applications, soil is mostly modeled in 3 layers, therefore limiting the number of the layers dose not put the generality of the program at risk. Through changing the pile properties such as stiffness (EI) and diameter, it is possible to model the different types of piles including, metal, concrete, wooden piles, etc with the various sections.

This program has only been written for piles with the free head, however for piles with the fixed head, the boundary conditions should be changed accordingly. Also, the program is employed only for analyzing the piles subjected to the lateral loads and implementation of the vertical loads is not allowed. Also, it is not possible to implement the lateral loads along the pile.

The equivalent spring method: In this method similar to designing the flexible shallow foundation, soil is considered as a set of elastic springs which they are very close together. Considering that this method was first proposed by WINKLER so this foundation is called WINKLER foundation. The elastic constant of these supposed springs is called the bearing capacity factor $\mathrm{K}$. for having a better understanding, consider the mentioned beam (i) of the last section (FDM) with a unit width and under the point load $f$ and the soil reaction q. From material strength:

$$
E I \frac{d^{4} w}{d x^{4}}=-q
$$

On the other hand, by defining the stiffness of the equivalent spring, the soil reaction is:

$$
\mathrm{Q}=\mathrm{kW}
$$

As a result:

$$
E I \frac{d^{4} w}{d x^{4}}=-k w
$$

The Eq. 11 has a result like Eq. 12 in which, $\mathrm{A}$ and $\mathrm{B}$ are the constant coefficients and $\beta=\sqrt[4]{\frac{\mathrm{k}}{4 \mathrm{EI}}}$ :

$$
\mathrm{w}=\mathrm{e}^{-\alpha \mathrm{x}}(\mathrm{A} \cos \beta \mathrm{x}+\mathrm{B} \sin \beta \mathrm{x})
$$

\section{RESULTS AND DISCUSION}

In the present research, the influence of the different parameters on the pile reaction is investigated using the two definitions:

- The influence of the soil strafication around the pile: In this definition, by changing the modulus of elasticity of the soil around the pile, the pile reaction is investigated. The modulus of elasticity of each layer has linearly changed. The employed modulus of elasticity are in a range between the semi-rigid clay to the semi-dense sand. The modulus of elasticity of the bottom layer is $12000 \mathrm{KN} . \mathrm{m}^{-2}$ and the amount of load is $300 \mathrm{kN}$. The pile length is $15 \mathrm{~m}$ which all the mentioned parameters can easily be shown in Fig. 2. Also, the diagrams of the displacement and the bending moment of the piles are shown in Fig. 3-6 $6^{[6-8]}$

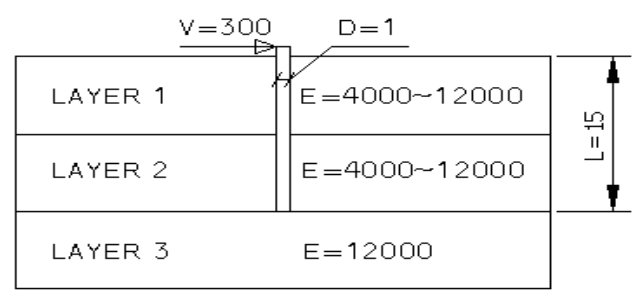

Fig. 2: The required parameters for analysis 


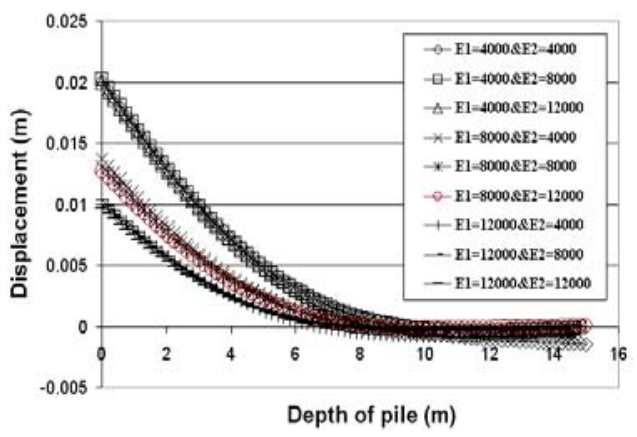

Fig. 3: The pile displacement versus the depth of the pile considering different types of soil (FDM)

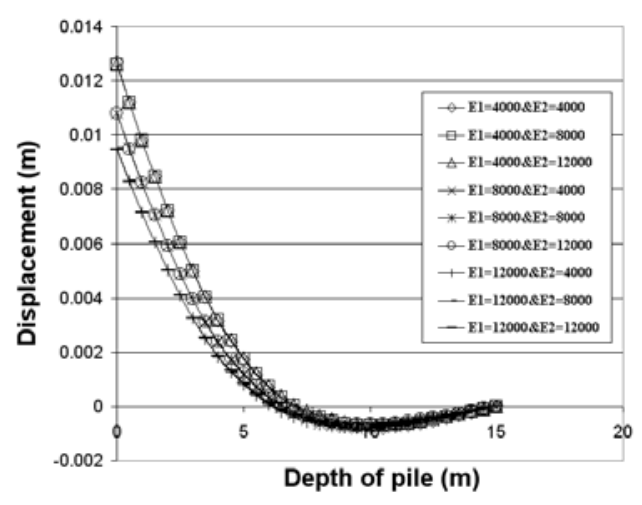

Fig. 4: The pile displacement versus the depth of the pile considering different types of soil (Equivalent spring method)

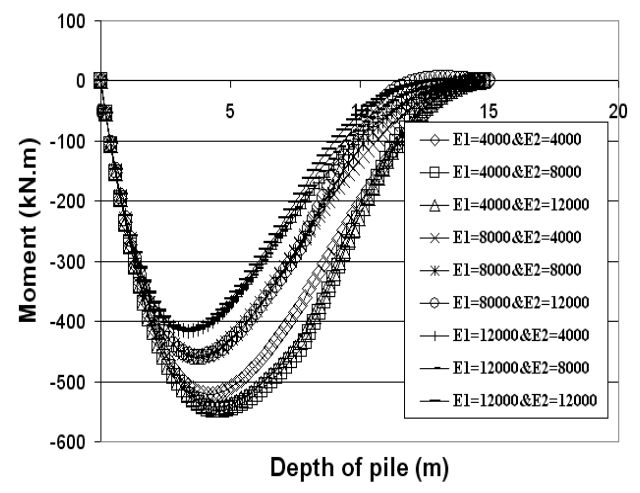

Fig. 5: The bending moment versus the depth of the pile considering different types of soil (FDM)

- The influence of the length of the pile: In this definition, by changing the length of the pile, the results are produced. Like the previous section the modulus of elasticity at the bottom layer was $12000 \mathrm{KN} . \mathrm{m}^{-2}$. The length of the pile is changed

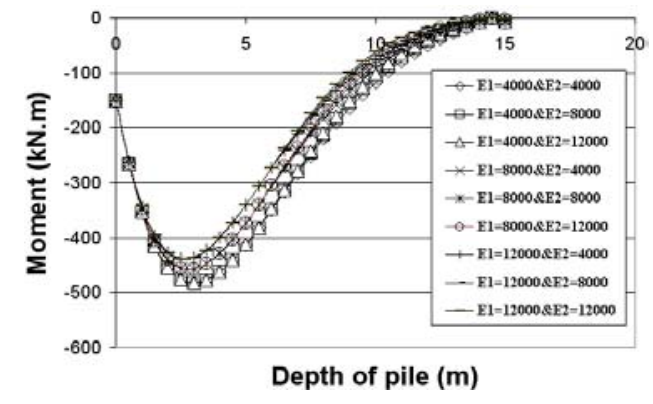

Fig. 6: The bending moment versus the depth of the pile considering different types of soil (Equivalent spring method)

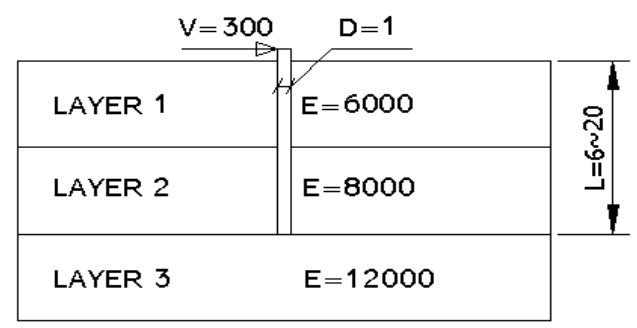

Fig. 7: The necessary parameters for analysis

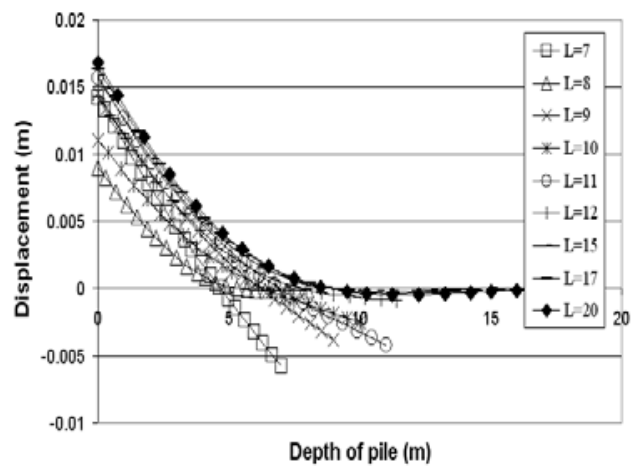

Fig. 8: The pile displacement versus the depth of the pile considering the change of the pile length (FDM)

from 6-20 $\mathrm{m}$ which are in a range between the short pile and the long pile. The amounts of the modulus of elasticity for the above layers are 6000 $\mathrm{KN} \cdot \mathrm{m}^{-2}$ and $8000 \mathrm{KN} . \mathrm{m}^{-2}$, respectively and the amount of the load is $300 \mathrm{kN}$. Figure 7 shows these parameters. Also, the displacement and the moment curves are shown in Fig. 8-11, respectively. All employed unites are in SI system. It should be reminded that, since it is not possible to model the soil under the pile using the equivalent spring method so the FDM is employed 
Am. J. Engg. \& Applied Sci., 1 (1): 76-81, 2008

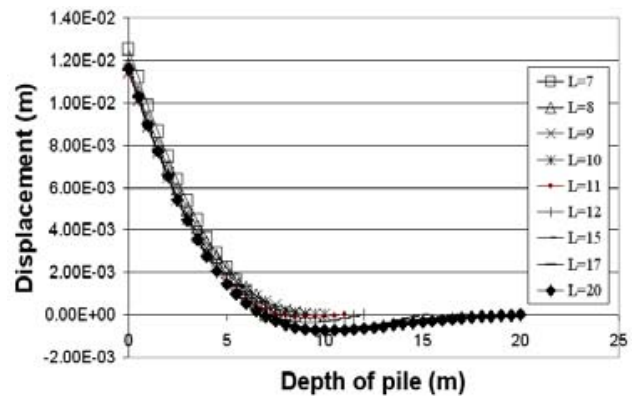

Fig. 9: The pile displacement versus the depth of the pile considering the change of the pile length (Equivalent spring method)

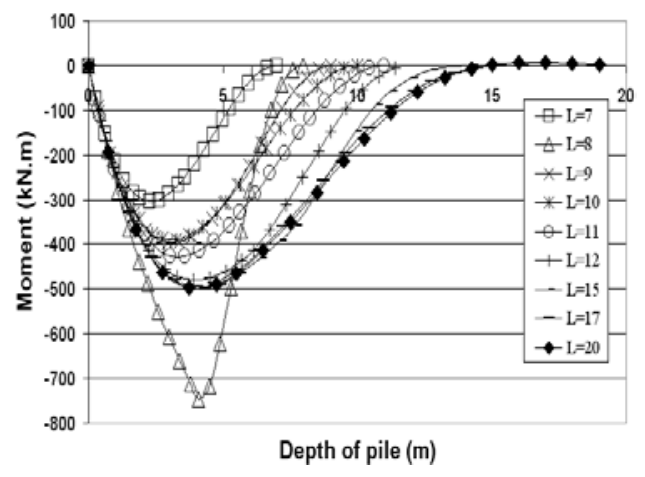

Fig. 10: The bending moment versus the depth of the pile considering the change of the pile length (FDM)

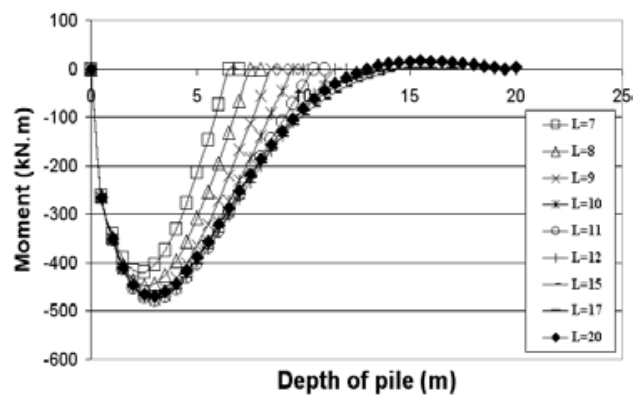

Fig. 11: The bending moment versus the depth of the pile considering the change of the pile length (Equivalent spring method)

\section{CONCLUSION}

- The effect of the soil strafication around the pile: In the displacement curve, the most influence on the pile displacement (it can be seen at the head of the pile) was produced by the above layer and the weakness of the above layer can increase the displacement of the pile head. The differences between the available displacement due to the changes of the modulus of elasticity of the bottom layers is not considerable and can be waived, therefore in order to control the displacement of the pile head, the modification of the limited depth of the pile could be very effective. The obtained results for displacement using the equivalent spring method are in a good agreement with those results obtained by FDM program and the maximum amount of difference is about $7 \%$. In this method, the effect of the above layer on the pile displacement can also be seen. In the bending moment diagram, similar to the displacement diagram, the most influence is related to the above layer. Besides, for the soils in the above layers with a less modulus of elasticity, the changes of this modulus in the bottom layers could affect the bending moment. The obtained results of the bending moment from the equivalent spring analysis is acceptable and a difference about $13 \%$ can be seen in compassion to those results obtained by FDM, but in this method the bending moment(for the calculating layer) is less affected by the above layer

- The influence of the pile length: It can easily be seen in the displacement plots that the pile length could have a substantial influence on the maximum displacement at the pile end, however this influence decreases from a particular length $(9 \mathrm{~m}$ in this case). This length is known as the length of fixity, so if the pile length is longer than this length, it is called long pile, otherwise called short pile, even though it still depends on other factors. In short piles, the sensitivity of maximum displacement of the pile is grater than the pile length, however with increasing the length, this sensitivity is decreased. Another point is that short piles behave linearly but long piles behave nonlinearly. In the bending moment plot (Fig. 10), like before, the maximum moment in the short piles is affected further by the length comparing to the long piles. In equivalent spring method (Fig. 10 and 11) reasoning that the pin-support is placed at the end of the pile, the pile is particularly modeled as a long pile. Thus, the change of the length doesn't considerably affect the amount of the displacement as well as the bending moment. Any way, the difference between the two applied methods is acceptable (about 17\%)

- By the same analysis, the soil under the pile is changed so the fallowing results are found: As it can easily be seen in the displacement diagrams, 
the influence of the bottom layers of the pile on the maximum displacement is very small and in the range of $\mathrm{E}=4000-12000 \mathrm{KN} . \mathrm{m}^{-2}$, the maximum amount of the displacement changes is about $5 \%$. In the bending moment diagram, similar to the lastly mentioned part, the maximum amount of the bending moment has not completely been affected by its above layer and the maximum difference is less than $15 \%$

Considering the above mentioned points, it can be mentioned that, installing the piles carrying only lateral loads in the high resistant layers is less effective.

\section{REFERENCES}

1. Basu, D. and R. Salgado, 2007. Elastic analysis of laterally loaded pile in multi-layered soil. J. Geomech. Geoeng., 2(3): 183-196, doi: 10.1080/1748 6020701401007.

2. Yang, K. and R. Liang, 2006. Numerical solution for laterally loaded piles in a two-layer soil profile. J. Geotech. and Geoenvir. Engrg., 132(11): 14361443, doi:10.1061/(ASCE)10900241(2006)132:11( 1436).

3. Shen, W.Y. and C.I. Teh, 2004. Analysis of laterally loaded piles in soil with stiffness increasing with depth. J. Geotech. and Geoenvir. Engrg., $130(8)$ : 878-882, doi: 10.1061/(ASCE)1090-0241(2004)130:8(878).
4. Yang, Z. and B. Jeremi, 2002. Numerical analysis of pile behaviour under lateral loads in layered elastic-plastic soils Int. J. Num. Analy. Methods in Geomechanics., 26(14): 1385-1406, doi: 10.1002/nag.250.

5. Almeida, V. S. and J. B. de Paiva, 2007. Static analysis of soil/pile interaction in layered soil by BEM/BEM coupling. J. Advances in Engineering Software.,38(11-12):835-845,doi:10.1016/j.adveng soft.2006.08.034.

6. Pan J. L., A. T. C. Goh, K. S. Wong and A. R. Selby, 2002. Three-dimensional analysis of single pile response to lateral soil movements. Int. J. Num. Analy. Methods in Geomechanics,. 26(8): 747-758, doi: 10.1002/nag.218.

7. Zhang, L., F. Silva and R. Grismala, 2005. Ultimate lateral resistance to piles in cohesionless soils. J. Geotech. and Geoenvir. Engrg., 131:78-83, doi: 10.1061/(ASCE)1090-0 241(2005)131:1(78).

8. Mazurenko , L. V. , 1978. Investigation of certain problems of the behavior of piles for hydraulic structures, J. Power Technology and Engineering. 12(3):259-268, doi: 10.1007/BF02305568. 